\title{
Risk Factors and Etiologies of Pediatric Acute Respiratory Distress Syndrome
}

\author{
Joseph G. Kohne and Heidi R. Flori
}

In the original description of what Ashbaugh and colleagues described as "the acute respiratory distress syndrome in adults" in 1967, special attention was paid to the inciting illness or injury (e.g., severe trauma, viral infection, acute pancreatitis) and possible contributing factors (e.g., hypotension, acidosis, fluid overload) [1]. Interestingly, of the 12 patients that Ashbaugh and colleagues described in that article, 4 of the 12 were aged 19 years or younger and may have been managed in pediatric critical care units today. That initial description has since evolved into the American European Consensus Conference (AECC) definition in 1994 and then the current Berlin definition of ARDS for adults and the Pediatric Acute Lung Injury Consensus Conference (PALICC) definition of pediatric ARDS (PARDS) [2-4]. Throughout these iterations, much attention continues to be paid toward understanding what conditions place patients at particular risk for ARDS development and what conditions contribute to worse ARDS clinical outcomes. This intense work is imperative in order to identify potentially modifiable factors that would decrease risk, improve monitoring of at-risk patients to prevent precipitous deteriora-

J. G. Kohne · H. R. Flori $(\bowtie)$

University of Michigan, Department of Pediatrics, Division of Pediatric Critical Care,

Ann Arbor, MI, USA

e-mail: heidiflo@med.umich.edu tion, and ultimately determine more personalized and precise approaches to management of those at highest risk or those with ARDS once established.

Risk factors associated with acute respiratory distress syndrome, whether in adults (ARDS) or pediatrics (PARDS), traditionally and originally consisted of the diagnoses most often associated with ARDS or PARDS development. This chapter takes these diagnoses into great account. Fortunately, this field of research has expanded to include relevant comorbidities associated with ARDS/PARDS development and/or severity. As the last 30 years have yielded important understanding into the pathobiology of ARDS/PARDS (see Chap. 3), so too have biological markers (aka biomarkers) and markers associated with genetic risk of ARDS/PARDS come to the forefront. Finally, discussions of ARDS/PARDS risk factors must inevitably dissect out whether the risk factors are associated with the development of ARDS/PARDS, and thereby factors impacting those patients at risk of ARDS/PARDS development, as well as those factors associated with better or worse clinical outcome once ARDS/ PARDS has been established.

Finally, much of this work has now demanded that both clinicians and researchers refine our discourse to further acknowledge that, as a syndrome, certain subgroups of patients, oft termed endotypes or sub-phenotypes, must exist that ultimately can be at inherently greater risk of disease and/or have unique pathophysiological 
responses that may make these subgroups of patients more or less able to respond to certain treatment strategies. Accordingly, prognostic risk factors describe factors associated with subgroups of patients at inherently greater risk of ARDS/PARDS, whereas predictive risk factors identify subgroups of patients that are at greater/ lesser likelihood of responding to certain treatment strategies based on inherent differences in their underlying pathophysiologic responses to illness/injury.

This chapter is intended to address all the areas outlined previously. These aspects inevitably dovetail significantly with (a) the epidemiology of PARDS, (b) pathophysiology of PARDS, and (c) relevant clinical outcomes of PARDS patients, both short and long term, each of which are covered in separate chapters in this book.

\section{Identifying Patients at Risk}

Identifying risk factors and understanding which patients are at risk for developing ARDS is significantly important to be able to develop preventative and early interventions. The US Critical Illness and Injury Trials Group (USCIIT): Lung Injury Prevention Study Investigators in 2013 developed a Lung Injury Prediction Score (LIPS) to identify patients at high risk for development of acute lung injury [5]. USCIIT researchers combined predisposing conditions (e.g., highrisk trauma, high-risk surgery, aspiration, sepsis, shock, and pneumonia) with risk modifiers such as alcohol abuse, acidosis, tachypnea, and $\mathrm{FiO}_{2}$ greater than 0.35 to create this scoring system. The scoring system was able to identify patients at risk of developing ALI using a cutoff score of 4 , with a positive likelihood ratio of 3.1 (95\% CI 2.9-3.4) and a negative likelihood ratio of 0.4 (95\% CI 0.3-0.5).

Similarly, with increasing use of noninvasive mechanical ventilation, both clinicians and researchers have wisely recognized that ARDS pathophysiology may begin before the onset of invasive mechanical ventilation, and identification of those patients before severe hypoxemia develops may be associated with improved survival $[6,7]$. Accordingly, the PALICC authors also noted the importance of identifying pediatric patients earlier and proposed a definition for patients "at risk" of PARDS which requires new pulmonary infiltrates on chest radiograph within seven days of a "known clinical insult" and supplemental oxygen requirement delivered via an invasive or noninvasive mechanism that does not meet OI or OSI criteria for PARDS [8]. This "at risk" population will certainly be an ongoing and future target for research into prevention and risk modification in PARDS.

\section{Comorbidities Associated with PARDS Development}

\section{Immunodeficiency}

It has been long understood that both adult and pediatric patients with preexisting immunodeficiency are at increased risk of both development of ARDS and worse outcomes after ARDS [9]. In the largest ARDS epidemiologic study in adults (LUNG SAFE), $20.8 \%$ of patients with ARDS were identified as having some form of immunocompromised state [10]. These patients had proportionally more infections as the etiology of the ARDS and had worse outcomes, including higher ICU and hospital mortality. In pediatrics, much of the early data on immunodeficiency came from human immunodeficiency virus (HIV). Most recently, Dr. Kitchin and colleagues published their experience in 90 children with HIV admitted to the PICU in South Africa meeting AECC criteria in 2008-2009 in which the authors identify high rates of opportunistic infections (33\% with P. jirovecii, 38\% with cytomegalovirus) and overall $30 \%$ mortality [11]. Another significant population with immune dysfunction is patients with cancer or immunosuppression related to chemotherapy. In the Pediatric Acute Respiratory Distress syndrome Incidence and Epidemiology study (PARDIE), $8 \%$ of all PARDS patients were identified as having cancer and $13 \%$ had immune suppression [12]. The outcomes for the groups were a disheartening $51 \%$ and $46 \%$ mortality, respectively. Dr. Rowan and colleagues have focused on the outcomes of hematopoietic stem cell transplant (HSCT) 
patients in the ICU (see Chap. 15). Their work has shown that HSCT patients who have respiratory failure often meet PARDS criteria (91\% in the first week of mechanical ventilation) and their disease is often severe, with longer ventilation courses and increased mortality [13, 14].

\section{Weight Extremes}

There seems to be an interesting interplay between ARDS and body habitus in both adults and children. Results from the 2011-2012 National Health and Nutrition Examination Survey (NHANES) indicate that $3.5 \%$ of children and adolescents in the United States are underweight and $31.8 \%$ are overweight or obese $[15,16]$. Both represent states of malnutrition and are known to be associated with a variety of comorbidities. Increasing BMI has been shown to be independently associated with increased risk of ARDS development. Further, while underweight adults with ARDS have high rates of mortality, obese individuals, particularly those with established ARDS, require longer intensive care unit (ICU) and hospital stays (LOS), but exhibit the lowest risk of in-hospital mortality when compared to other weight categories [17]. This has come to be known as the "obesity paradox." This "obesity paradox" has been reported in adults with sepsis or ARDS [18]. Obese individuals, who exhibit chronic inflammation and endothelial activation, surprisingly have reduced systemic inflammatory response with ARDS compared to those of normal weight [19], suggesting a possible protective attenuation of the immune response to critical illness [19]. In a cohort of 330 subjects, Ward and colleagues found that $28 \%$ of PARDS patients were obese, and the obesity paradox was observed in those whose PARDS was due to systemic illness [20]. Not surprisingly, the underweight exhibited the highest odds of in-hospital death.

\section{Environmental Factors}

Because of the acute onset and often clear catastrophic trigger, such as septic shock or major trauma, the importance of the environment and patient's air quality on ARDS development can be inappropriately discounted, unlike in disease processes such as asthma or chronic obstructive pulmonary disease. However, adult ARDS has been clearly shown to be affected by cigarette smoking, so it is not unreasonable to think that environmental smoke exposure could affect PARDS. In the adult ARDS population, Dr. Calfee and colleagues demonstrated that cigarette smoking by history and a biomarker of smoke exposure, 4-(methylnitrosamino)-1-(3-pyridyl)-1-butanol, were each associated with the development of ARDS in patients with sepsis [21]. Impaired fluid clearance, epithelial and endothelial effects, and immune modulation could all underlie this effect [21]. In an allied study, Reilly and colleagues studied 996 critically ill adult trauma patients in conjunction with air quality metrics in the 6 weeks prior to presentation. Interestingly, nitrogen dioxide, sulfur dioxide, and particulate matter $<2.5$ micrometers over the 6 weeks were significantly associated with ARDS development [22]. Further investigation into PARDS may reveal other predisposing environmental factors including environmental smoke exposure and ambient air pollution as risk factors for development of or more serious PARDS [23].

\section{Age/Gender/Race and Ethnicity}

It is well known that the immune system develops and assumes more complexity with age [2426], and that children represent a more heterogenous patient population compared to adults with regard to predisposing conditions, etiology, and response to therapy [27]. The exact impact of age on risk of development of ARDS and severity of ARDS remains incompletely elucidated. Nonetheless, epidemiologic studies to date do not consistently endorse differential PARDS outcomes based on age, with some suggesting increasing risk with older age, but most studies suggesting no association of age with PARDS outcome [7, 9]. Similarly, these studies also do not show any differential risk of worse clinical outcomes with either male or female gender. 
Similarly, risk factors for outcomes of ARDS patients from different racial and ethnic backgrounds are also incompletely investigated. Adult studies suggest increased risk of death in some African American and Hispanic ARDS cohorts [28] and differential response to treatments, as was determined post hoc in the NIH-funded Fluid and Catheter Treatment Trial [29]. Pediatric studies of PARDS patients, likely because of limited study size, have not consistently observed increased risk within racial or ethnic groups either. While the PARDIE study results did not indicate increased risk of death across different racial groups, mortality was significantly higher in Hispanic cohorts $(24.4 \%)$ compared with nonHispanic patients $(14.8 \%)$ or those with other ethnicity $(14.4 \%, p=0.013)$ [12]. Finally, these studies do not address the racial or ethnic impact on the risks of development of ARDS or PARDS, which may have an entirely different risk profile and may better be studied from a genetic risk perspective. As an example, Dahmer and colleagues have determined genetic polymorphisms in the genes of factors involved in the splicing cystic fibrosis transmembrane regulator conductance associated with increased risk of pneumoniaassociated PARDS development in African American and non-Hispanic Caucasian children [30]. Again, this area is likely to be more completely examined in the years to come.

\section{Genetic Factors}

Investigations focusing on the genetic contribution to PARDS development are inherently fraught with challenges including, but not limited to, (a) the wide array of disease states associated with PARDS development; (b) the PARDS diagnosis itself, by definition, being a syndrome rather than a clearly defined entity with a proven diagnostic confirmatory test; and (c) the large number of patients required to complete genomic studies with adequate power. That said, genomic approaches offer promising opportunities to identify novel mechanistic pathways of disease that may offer pharmacologic or other therapeutic targets in the future. Certainly, as latent class analytic strategies identify sub-phenotypes of ARDS patients with differential risk of response to therapy or distinct clinical outcomes, investigations of genetic variants may offer areas of common biology within sub-phenotypes or may identify previously unidentified sub-phenotypes. To date, although multiple single-nucleotide polymorphisms (SNPs) have been identified with some association to ARDS risk, almost all studies have been done in adults. Not surprisingly, reproducibility has been problematic. The most notable functional variants identified to date are variants encoding angiotensin-converting enzyme (ACE) and surfactant protein B (SFTPB), with the most potentially pharmacologically targetable SNPs identified to date being angiopoietin-2 (ANGPT2) and IL-1 receptor antagonist $(I L 1 R N)$ [31]. To confirm the functional significance of dysregulated coagulation in contributing to worse outcome in ARDS, genetic studies from patients enrolled in the adult ARDSnet Fluid and Catheter Treatment Trial reported that genetic variants in thrombomodulin and endothelial protein $\mathrm{C}$ receptor genes were independently associated with mortality, independent of treatment trial allocation [32]. The finding that the ILIRN coding variant is associated with decreased risk of ARDS in adults supports the understanding that IL-1beta and other IL-1 pathway cytokines are causally implicated in ARDS risk [33]. However, in a study of 549 children with acute respiratory failure, Dahmer and colleagues were unable to identify genetic variants in the IL-1 pathway genes that were associated with PARDS [34]. Initiated in 2012, NHLBI hosted an exome sequencing project that includes an investigation of 45,000 SNPs from the exomes of adults with ARDS and healthy controls. Through this project, the regulatory gene arylsulfatase D (ASRD) was identified to be present in $22 \%$ of adults with ARDS and $4 \%$ of controls, and a protein coding gene, XK Kell blood group complex member 3 (XKR3), was present with a minor allele frequency of $37 \%$ in ARDS patients and $4 \%$ of controls [35]. More is certain to come.

Although many investigations are currently underway, far fewer publications exist on the genetic associations in established PARDS 
patients or patients at risk for PARDS. Wei and colleagues identified linkage disequilibrium and different allelic or genotypic frequencies in nitric oxide synthesis 3 polymorphisms measured in 216 PARDS patients in comparison to 225 healthy controls [36]. As mentioned earlier, Perez-Marquez, Dahmer, and colleagues determined potential racial and ethnic contributions to PARDS development in pediatric patients with community-acquired pneumonia [30]. Specifically, this group identified 5 variants in cystic fibrosis transmembrane conductance regulator $(C F T R)$ splicing factor genes independently associated with PARDS in African American children without cystic fibrosis but with PARDS secondary to community-acquired pneumonia. An additional variant was identified in nonHispanic Caucasian children, also without cystic fibrosis, that was associated with increased risk of PARDS development. CFTR, a chloride channel in alveolar epithelial cells, has long been understood to be integral to maintenance of fluid homeostasis in the lung and impaired during ARDS as alveolar epithelial cell injury propagates.

\section{Etiologies Associated with PARDS Development}

Not surprisingly, more research has been completed into the risk factors associated with the development of ARDS in adults compared to pediatric populations. Diagnoses most commonly associated with adult ARDS include pneumonia, extrapulmonary sepsis, aspiration, noncardiogenic shock, and trauma [37, 38]. Understanding of the association with ARDS development has been so ingrained, that recent studies indicate that clinicians may "miss" ARDS diagnoses in those patients that present with no known risk factor [39].

One frequent assumption is that ARDS in pediatric patients is more often related to a direct lung injury than seen in adults. We can test this consideration by comparing the epidemiology of adult ARDS and PARDS through the lens of two large international cohort studies.
In adults, the Large Observational Study to Understand the Global Impact of Severe Respiratory Failure (LUNG SAFE) investigators recruited a sample of 29,144 patients from 459 ICUs and identified 3022 patients with ARDS using the Berlin definition [40]. Of those patients, $59.4 \%$ had pneumonia as a risk factor for ARDS, followed by $14.2 \%$ with extrapulmonary sepsis, $14.2 \%$ with aspiration, $7.5 \%$ with noncardiogenic shock, and $4.2 \%$ with trauma. No risk factor was identified in $8.3 \%$ of patients.

In pediatrics, the PARDIE study was an international point prevalence study surveying over 23,000 PICU admissions and 12,000 patients requiring mechanical ventilation [12]. Of those patients, $744(3.2 \%)$ were identified as having PARDS based on PALICC criteria. Among PARDS patients, the most common risk factor was pneumonia or lower respiratory tract infection $(63 \%)$, distantly followed by sepsis $(19 \%)$, aspiration (8\%), trauma (4\%), other (3\%), drowning (1\%), and non-septic shock (1\%). Therefore, although the Berlin and PALICC definitions for ARDS differ, the results of these two large epidemiologic studies strongly indicate that the etiologies of PARDS and ARDS may not be as disparate as is sometimes assumed.

Most descriptions of ARDS and PARDS break down the etiology into direct and indirect causes. The Pediatric Acute and Critical Care Medicine Asian Network (PACCMAN) published a study in 2018 comparing "pulmonary" versus "extrapulmonary" ARDS [41]. The "extrapulmonary" group included patients with sepsis, massive transfusions, burns, multi-trauma, and hemorrhagic shock and comprised 41 (13.4\%) of the 307 patients with PARDS. In this cohort, the extrapulmonary group had higher mortality, higher proportion of multiple organ dysfunction, and higher median oxygenation index. A similar study in adults examined 417 patients with ARDS by AECC criteria: 250 (60\%) with direct ARDS defined as pneumonia or aspiration and 167 (40\%) with indirect ARDS defined as nonpulmonary sepsis or pancreatitis [42]. The authors showed similar mortality (28\% direct vs $21 \%$ indirect) between the two groups, but the direct group had higher lung injury scores (3.0 vs 
2.8 ) and the indirect group had more organ dysfunction (median 2 vs 1 organ system).

\section{Direct Lung Injury}

\section{Primary Pulmonary Infections}

Primary pulmonary infections were the most common cause of PARDS in the PARDIE study, underlying two-thirds of the cases of PARDS identified. These "direct" PARDS cases had lower mortality than "indirect" causes like sepsis and non-septic shock [12]. Primary pulmonary infections leading to ARDS can be related to a viral etiology, bacterial etiology, or both as in the case of influenza leading to a Staphylococcus aureus infection. Much attention has been paid to pandemic viruses that can lead to drastic increases in ARDS patients: influenza, including H1N1; Middle Eastern respiratory syndrome coronavirus; and severe acute respiratory syndrome coronavirus [43]. Interestingly, the extreme virulence of these coronavirus infections is now thought to be immune mediated, with very early and exaggerated activation of the complement cascade [44]. More commonly, viral etiologies are those that cause the upper respiratory infections and bronchiolitis cases commonly encountered in the pediatric intensive care unit: respiratory syncytial virus (RSV), adenovirus, rhinovirus, and human metapneumovirus [43, 45]. Similarly, bacterial causes of PARDS are often the common pathogens that cause community-acquired pneumonia including Streptococcus pneumoniae, Haemophilus influenzae, and Staphylococcus aureus [46]. As expected, immunosuppression also places patients at greater risk for fungal and parasitic causes of ARDS, including Pneumocystis jirovecii [46]. These patients retain a higher mortality regardless of ARDS severity [10]. Finally, as the PALICC definition now also allows for patients with chronic lung disease to be diagnosed with PARDS, we may see an increase in pathogens specific to technology-dependent and chronically ventilated patients as important PARDS etiologies soon.

\section{Aspiration}

Aspiration was identified as the third most common etiology of PARDS in the PARDIE study, underlying $8 \%$ of the incidence seen. Aspiration is most commonly thought of as aspiration of stomach contents but can also be from the aspiration of household chemicals, blood, and other substances. Swallowing dysfunction or altered consciousness places a patient at risk for inhalation of such pharyngeal contents. Further, the acidity of stomach contents can lead to direct pulmonary epithelial damage and neutrophilic inflammation [47], commonly described as "chemical pneumonitis." Bacteria from the digestive tract can also cause secondary aspiration pneumonia [47].

\section{Trauma}

The development of ARDS following trauma is multifactorial and can differ from other mechanisms leading to ARDS. It can be a result of both direct thoracic trauma, including pulmonary contusion, or secondary to inflammation and infection that develop after major trauma [48]. The pathophysiology of trauma-induced ARDS also seems to be different than other etiologies: biomarkers including von Willebrand factor antigen, intercellular adhesion molecule-1 (ICAM-1), and surfactant protein-D have been found to be lower in trauma patients than in other processes leading to ARDS [49].

Interestingly, both the LUNG SAFE and PARDIE studies described similar prevalence of trauma (4\%) as an inciting factor for ARDS. Several studies have used the National Trauma Databank (NTDB) to evaluate the epidemiology of pediatric trauma-induced ARDS. Killien and colleagues examined 146,058 children $<18$ years old admitted to 460 level I or II adult or pediatric trauma centers from 2007 to 2016. ARDS incidence was $1.8 \%$ in all pediatric trauma patients and $3.8 \%$ in mechanically ventilated trauma patients. Injury severity score (ISS) was a strong risk factor for ARDS, and overall injury severity was more predictive of outcome than chest trauma alone [50]. 
The authors also identified that very few patients who went on to develop ARDS had a normal Glasgow coma scale (GCS) or respiratory rate on arrival to the emergency department (ED). The mortality in patients who developed ARDS was $20 \%$. In Dr. Killien's study, motor vehicle crashes were the most common mechanism among those with ARDS. In another study using the NTDB, de Roulet and colleagues demonstrated that, in young children, non-accidental injury and near drowning were independently associated with the development of ARDS [51].

\section{Indirect Lung Injury}

\section{Sepsis}

Following respiratory infections, sepsis is the next most common etiology of PARDS [12]. The endothelial activation, cytokine-mediated inflammation, reactive oxygen species, and disruption of normal coagulation cascades present in patients with severe sepsis can lead to the development of diffuse alveolar damage [52]. Given that the inflammation in sepsis is thought to trigger the inflammation and cell damage in ARDS, studies have attempted to target this group specifically for anti-inflammatory therapies $[53,54]$. A detailed discussion of sepsis is beyond the scope of this chapter, but further investigation into the pathophysiology and common pathways of both diseases can lead to therapeutic targets.

\section{Transfusion Related}

Transfusion of blood products is an uncommon but significant cause of acute lung injury and ARDS. Consensus definitions of transfusionrelated acute lung injury (TRALI) mirror the AECC and Berlin definitions of ARDS except that lung injury and subsequent ARDS develop during or within 6 hours of the transfusion [55, 56]. TRALI may be considered a "two-hit" phenomenon with the first hit being the patient's disease process and the second hit being neutrophil activation and capillary leak $[52,57]$. Both adult and pediatric investigators have confirmed that transfusions of multiple blood products, particularly those that are protein-rich, such as fresh frozen plasma and platelets, are associated with both development of ARDS (TRALI) and unfavorable outcomes of ARDS, including greater mortality [58-60].

\section{Noninfectious Systemic Inflammation}

Any disease process that results in a systemic inflammatory response places a patient at risk for ARDS. One classic example is the lung injury that develops with acute pancreatitis, which was also noted by Ashbaugh et al. in 1967. The inflammatory cytokines and chemokines released result in both vascular endothelial and alveolar epithelial damage, potentially exacerbated by pancreatic enzymes and a compromised intestinal barrier [61]. The common pathway of vascular permeability and fluid leak that often underlies ARDS follows. Another common mechanism of systemic inflammation is the ischemia and reperfusion that occurs during cardiopulmonary bypass for congenital heart defect surgical repair. This can lead to multiple organ dysfunction syndrome (MODS) including ARDS; however, outcomes are significantly better with MODS after bypass than other forms [62].

\section{Modifiable Aspects of Care Delivery}

Among all etiologies for ARDS, perhaps the most interesting and potentially meaningful area of focus is the potentially modifiable areas of the care we deliver to patients with acute respiratory failure. These methods of respiratory support, medications, and health care delivery are all potential targets to prevent the development of ARDS in at-risk patients. A large study by the Practice of Ventilation in critically ill adults without ARDS at onset of ventilation (PRoVENT) study group attempted to identify these factors [63]. This international, multicenter cohort study identified patients undergoing mechanical ventilation who were at risk of ARDS defined as a 
Lung Injury Prevention Score of 4 or higher. Ventilator variables such as tidal volume, PEEP, and driving pressure were not associated with the development of ARDS in those at risk and those not at risk, but interestingly $\mathrm{FiO}_{2}$ was higher in patients who developed ARDS. A noted limitation of this study as well as other efforts to prevent ARDS is the large number of patients who have ARDS at the time of intubation [64]. Raymondos and colleagues tested whether outcomes differed between ARDS patients managed at German university and nonuniversity hospitals and found a survival benefit in patients treated at university hospital [65]. Differences were seen in the use of higher $\mathrm{FiO}_{2}$, lower PEEP, and higher driving pressure in the nonuniversity hospitals at the time of the study. Interestingly, this finding corroborates that of Noah et al. from 2011 wherein transfer to an ECMO center, even if the patient was then not cannulated for ECMO, conferred a survival benefit for those adults with H1N1-associated ARDS compared to matched non-ECMO referred patients [66]. While these observational data do not point towards clear reasons for the improved survival, they suggest that differences in our routine and supportive care of patients at risk for ARDS development can affect progression of disease.

Coupled with the acknowledgement that best chances for complete recovery rest on earlier initiation of appropriate therapies, these studies all indicate a need to identify patients at earlier timepoints in their course. To affect this next type of research, researchers are likely to enroll patients at locations other than the pediatric intensive care unit, including the emergency department, operating rooms, and acute care hospital wards. The mission of the National Institutes of Healthfunded PETAL network (Prevention and Early Treatment of Acute Lung Injury, http://petalnet. org) includes partnering ICUs with EDs for earlier diagnosis and initiation of supportive measures. In pediatrics, in 2015, the PALICC yielded internationally accepted, comprehensive definitions for PARDS, patients at risk for PARDS, and patients with complex comorbidities previously oft excluded from PARDS-related research, such as chronic lung disease and congenital heart disease populations. The at-risk group is now defined as patients either on noninvasive positive pressure via nasal interface or patients on nasal cannula, either via traditional or heated high flow nasal cannula, with specified oxygenation deficits [8]. In the wake of the establishment of these pediatric-specific definitions, the PARDIE investigators recently completed an international, observational study of PARDS and at risk for PARDS patients. Initial results are now published on the traditional PARDS cohort with results related to the at-risk population, including data on potentially modifiable aspects of care, soon forthcoming [12].

\section{Less Common Etiologies of ARDS}

Case reports and case series describe the development of ARDS following episodes causing local or systemic inflammation including pulmonary air embolus [67], fat embolism [68], Still's disease [69], and malaria [70, 71]. Neurogenic pulmonary edema has been described in the setting of severe neurologic injury, potentially related to a large sympathetic surge following the injury [72].

\section{Biomarkers Associated with PARDS Onset and at Risk for PARDS Development}

Clearly the pathophysiologic processes of inflammation, vascular endothelial injury, alveolar epithelial injury, fibrosis, and hypercoagulability may be triggered and initiated well before patients are admitted to intensive care units [73]. Biomarker studies in children, as in adults, have identified evidence of lung injury even in the earliest days of hypoxemia and, in up to $25 \%$ of cases, before invasive mechanical ventilation has been initiated $[37,74]$.

Several researchers have observed elevations of markers of vascular endothelial injury at the onset of PARDS diagnosis. Flori and colleagues 
found that the highest levels of von Willebrand factor antigen were measured early in the course of PARDS [75] and Yehya et al. reported similar findings with angiopoietin-2, ANG2 [76]; both are vascular endothelial injury markers. Markers specific for alveolar epithelial injury are more difficult to measure in plasma. Flori and colleagues found early elevations of soluble intercellular adhesion molecule-1, sICAM-1 [77], also a marker of macrophage activation, and Yehya observed elevated levels of soluble receptor for advanced glycation end products, sRAGE, at PARDS diagnosis [76]. Sapru and colleagues identified early activation of multiple markers of the inflammatory and coagulation cascades [78, 79]. Zinter et al. observed early evidence of matrix metalloproteinase release into the plasma, an indicator of early-onset fibrosis, again at PARDS onset. Finally, the pathogenesis of ARDS is felt to be mediated by both pathogen-associated molecular patterns (PAMPs) and damageassociated molecular patterns (DAMPs), biomolecules that can perpetuate an inflammatory response. Circulating nucleosomes are released after cellular injury into the bloodstream, acting as DAMPs, and contributing to the severity of ARDS. Yehya et al. have measured circulating nucleosomes in children with PARDS and found striking and independent associations with mortality and non-pulmonary organ failure and severity of oxygenation defect [80]. Most of these studies included PARDS patients who were not only invasively mechanically ventilated but also those patients meeting PARDS criteria while on noninvasive ventilation, which suggests that pathophysiology can be identified a bit earlier in these cascades.

These studies all reflect biomarkers associated with PARDS onset. As described previously, the next phases of research must strive to identify atrisk patients before they develop PARDS. Identification of these risk factors for development may help clinicians at the bedside to adjust monitoring and/or initiate lung protective management strategies earlier in the patients' course in order to prevent PARDS development entirely. Similarly, better identification of those patients at risk for PARDS development may enable researchers to develop novel therapies that can be initiated earlier in the patient's course and, likely, using noninvasive modalities (i.e., inhaled treatments, alternate modes of noninvasive respiratory support).

The RESTORE trial of sedation management in pediatric acute respiratory failure enrolled pediatric patients with acute respiratory failure requiring invasive mechanical ventilation secondary to primary pulmonary or airway disease [81]. As such, patients with acute respiratory failure secondary to trauma or surgery were excluded. Nonetheless, the RESTORE study has allowed for potential identification of children with acute respiratory failure yet prior to PARDS onset. Genetic Variation and Biomarkers in Children with Acute Lung Injury (BALI; R01HL095410) was a prospective ancillary study to the multisite clinical trial, Randomized Evaluation of Sedation Titration for Respiratory Failure (RESTORE; U01 HL086622) (22). BALI was designed to examine the association of specific plasma protein and genetic biomarkers with PARDS among prospectively enrolled children with acute respiratory failure. Twenty-two of the 31 PICUs participating in RESTORE volunteered to participate in this study. A total of $69 \%$ of the patients $(n=378)$ met the criteria for PARDS and $83 \%$ of children $(n=312)$ with PARDS met criteria on the day of intubation (study day 0$)$; another $11 \%(n=42)$ met criteria on study day 1 , and the remaining $6 \%$ met criteria on study days $2-5$. The level of plasma IL-1ra was significantly greater at intubation through day 3 in those with PARDS compared with those without PARDS $(p<0.0001)$. In addition, multivariable regression analysis of data across all days demonstrated a significant association of IL-1 ra (OR, 1.30; 95\% CI, 1.10-1.52; $p=0.002)$ and day $(p<0.05)$ on presence of PARDS, independent of age and PRISM-III. Additional data from BALI related to other markers of inflammation, plasma surfactant protein measurement, and markers of dysregulated coagulation are forthcoming. Despite this work and although RESTORE enrolled patients with acute respiratory failure, 
approximately $90 \%$ of patients meeting PARDS criteria did so within the first day of RESTORE enrollment, thereby again limiting the opportunity to find biomarkers that can be measured prior to PARDS onset and within a time frame to allow clinicians to use these marker measurements to initiate preventative therapies. These data corroborate nicely with adult data from the LUNG SAFE study wherein only $7 \%$ of adults that eventually developed ARDS did so after day 2 of acute hypoxemic respiratory failure [40].

\section{Latent Class Analysis and Identification of ARDS and PARDS Sub-phenotypes}

To date, no pharmacologic treatment has been conclusively proven effective in decreasing mortality or morbidity in adults or children with ARDS [82, 83]. The failure of the pharmacologic treatments tested thus far has recently been attributed, in part, to heterogeneity in patients with ARDS. Dr. Iwashyna and colleagues developed simulation models to demonstrate that heterogeneity in cohorts of patients with acute respiratory failure can significantly impact clinical trial results by: (a) showing no benefit for the entire cohort resulting in a negative trial although a high-risk subgroup (sub-phenotype) of patients may actually benefit from the treatment and (b) showing benefit for the entire cohort resulting in a positive trial though a subgroup (subphenotype) of patients may incur harm from the treatment [84]. The recent consensus in the field is that strategies aimed at prognostic (identifying high-risk patients) and predictive (selecting patients who are likely to respond to treatment based on differences in the underlying pathology) enrichment should be used in studies of ARDS patients to identify targeted therapies that have a higher likelihood of reducing morbidity and mortality.

Recently, Drs. Calfee and Delucci have used latent class analysis (LCA) to identify two novel sub-phenotypes in adult ARDS patients with different biomarker profiles, clinical and biological characteristics, clinical outcomes, and response to treatment [85-87]. Their team has since independently replicated the same two ARDS subphenotypes using data from additional NHLBI-funded adult ARDS trials (Table 4.1). The hyperinflammatory ARDS sub-phenotype, characterized in part by higher plasma inflammatory biomarkers (interleukin-6 (IL-6), IL-8, soluble tumor necrosis factor receptor-1 (sTNFr-1), plasminogen activator inhibitor-1 (PAI-1), angiopoietin-2 (Ang-2), receptor for advanced glycation end products (RAGE), and decreased protein C, is associated with $20-30 \%$ higher mortality and approximately 10-day longer length of mechanical ventilation (MV). The hyperinflammatory patients may preferentially benefit from higher PEEP and restrictive fluid strategies. The two sub-phenotypes appear to be stable to at least 3 days after meeting ARDS criteria. There are no studies identifying PARDS sub-phenotypes in children primarily because until recently there were no large cohorts of children with PARDS. Once again, this is assuredly "next to come" for this patient population.

Table 4.1 Differential response to treatment in ARDS sub-phenotypes

\begin{tabular}{l|l|l|l|l}
\hline & $\begin{array}{l}\text { Mortality in intervention } \\
\text { hypoinflammatory } \\
\text { sub-phenotype }\end{array}$ & $\begin{array}{l}\text { Mortality in intervention } \\
\text { hyperinflammatory } \\
\text { sub-phenotype }\end{array}$ & $\begin{array}{l}\text { Mortality in control } \\
\text { hypoinflammatory } \\
\text { sub-phenotype }\end{array}$ & $\begin{array}{l}\text { Mortality in control } \\
\text { hyperinflammatory } \\
\text { sub-phenotype }\end{array}$ \\
\hline ALVEOLI $^{\mathrm{a}}$ & $24 \%$ & $42 \%$ & $16 \%$ & $51 \%$ \\
\hline FACCT $^{\mathrm{a}}$ & $26 \%$ & $40 \%$ & $18 \%$ & $50 \%$ \\
\hline HARP $^{\mathrm{b}}$ & $17 \%$ & $32 \%$ & $16 \%$ & $45 \%$ \\
\hline
\end{tabular}

a0-day mortality

b28-day mortality 


\section{References}

1. Ashbaugh D, Boyd Bigelow D, Petty T, Levine B. Acute respiratory distress in adults. Lancet. 1967 Aug 12;290(7511):319-23.

2. Bernard GR, Artigas A, Brigham KL, Cat-let J, Falke K, Hudson L, et al. Report of the AmericanEuropean consensus conference on acute respiratory distress syndrome: definitions, mechanisms, relevant outcomes, and clinical trial coordination. Consensus Committee. J Crit Care. 1994 Mar;9(1):72-81.

3. Ranieri VM, Rubenfeld GD, Thompson BT, Ferguson ND, Caldwell E, Fan E, et al. Acute respiratory distress syndrome: the Berlin definition. JAMA. 2012 Jun 20;307(23):2526-33.

4. Pediatric Acute Lung Injury Consensus Conference Group TPALICC. Pediatric acute respiratory distress syndrome: consensus recommendations from the pediatric Acute lung injury consensus conference. Pediatr Crit Care Med. 2015 Jun;16(5):428-39.

5. Gajic O, Dabbagh O, Park PK, Adesanya A, Chang SY, Hou P, et al. Early identification of patients at risk of acute lung injury: evaluation of lung injury prediction score in a multicenter cohort study. Am J Respir Crit Care Med. 2011;183(4):462-70.

6. Zinter MS, Orwoll BE, Spicer AC, Alkhouli MF, Calfee CS, Matthay MA, et al. Incorporating inflammation into mortality risk in pediatric acute respiratory distress syndrome. Crit Care Med. 2017 May;45(5):858-66.

7. Flori HR, Glidden DV, Rutherford GW, Matthay MA. Pediatric acute lung injury: prospective evaluation of risk factors associated with mortality. Am J Respir Crit Care Med. 2005 May 1;171(9):995-1001.

8. Jouvet P, Thomas NJ, Willson DF, Erickson S, Khemani R, Smith L, et al. Pediatric acute respiratory distress syndrome: consensus recommendations from the pediatric acute lung injury consensus conference. Pediatr Crit Care Med. 2015;16:428-39.

9. Erickson S, Schibler A, Numa A, Nuthall G, Yung M, Pascoe E, et al. Acute lung injury in pediatric intensive care in Australia and New Zealand - a prospective, multicenter, observational study. Pediatr Crit Care Med. 2007 Jul;8(4):317-23.

10. Cortegiani A, Madotto F, Gregoretti C, Bellani G, Laffey JG, Pham T, et al. Immunocompromised patients with acute respiratory distress syndrome: secondary analysis of the LUNG SAFE database. Crit Care. 2018 Jun 12;22(1):157.

11. Kitchin OP, Masekela R, Becker P, Moodley T, Risenga SM, Green RJ. Outcome of human immunodeficiency virus-exposed and -infected children admitted to a pediatric intensive care unit for respiratory failure*. Pediatr Crit Care Med. 2012 Sep;13(5):516-9.

12. Khemani RG, Smith L, Lopez-Fernandez YM, Kwok J, Morzov R, Klein MJ, et al. Paediatric acute respiratory distress syndrome incidence and epidemiology (PARDIE): an international, observational study. Lancet Respir Med. 2018;2600(18):1-14.
13. Rowan CM, Smith LS, Loomis A, McArthur J, Gertz SJ, Fitzgerald JC, et al. Pediatric Acute respiratory distress syndrome in pediatric allogeneic hematopoietic stem cell transplants: a multicenter study. Pediatr Crit Care Med. 2017;18(4):304-9.

14. Rowan CM, Gertz SJ, McArthur J, Fitzgerald JC, Nitu ME, Loomis A, et al. Invasive mechanical ventilation and mortality in pediatric hematopoietic stem cell transplantation: a multicenter study. Pediatr Crit Care Med. 2016;17(4):294-302.

15. Ogden CL, Carroll MD, Kit BK, Flegal KM. Prevalence of childhood and adult obesity in the United States, 2011-2012. JAMA. 2014 Feb 26;311(8):806-14.

16. Fryar CD, Carroll MD, Ogden CL. Prevalence of underweight among children and adolescents Aged 2-19 Years: United States, 1963-1965 Through 2013-2014 [Internet]. CDC; 2018; Available from: https://www.cdc.gov/nchs/data/hestat/underweight_ child_15_16/underweight_child_15_16.htm.

17. Gong MN, Bajwa EK, Thompson BT, Christiani DC. Body mass index is associated with the development of acute respiratory distress syndrome. Thorax. 2010;65(1):44-50.

18. Zhi G, Xin W, Ying W, Guohong X, Shuying L. "Obesity paradox" in acute respiratory distress syndrome: asystematic review and meta-analysis, Zhao YY, editor. PLoS One. 2016 Sep 29;11(9):e0163677.

19. Stapleton RD, Dixon AE, Parsons PE, Ware LB, Suratt BT. The association between BMI and plasma cytokine levels in patients with acute lung injury. Chest. 2010 Sep;138(3):568-77.

20. Ward SL, Gildengorin V, Valentine SL, Sapru A, Curley MAQ, Thomas N, et al. Impact of weight extremes on clinical outcomes in pediatric Acute respiratory distress syndrome. Crit Care Med. 2016;44(11):2052-9.

21. Calfee CS, Matthay MA, Kangelaris KN, Siew ED, Janz DR, Bernard GR, et al. Cigarette smoke exposure and the acute respiratory distress syndrome. Crit Care Med. 2015 Sep;43(9):1790-7.

22. Reilly JP, Zhao Z, Shashaty MGS, Koyama T, Christie JD, Lanken PN, et al. Low to moderate air pollutant exposure and acute respiratory distress syndrome after severe trauma. Am J Respir Crit Care Med. 2018;6:rccm.201803-0435OC.

23. Lin H, Tao J, Kan H, Qian Z, Chen A, Du Y, et al. Ambient particulate matter air pollution associated with acute respiratory distress syndrome in Guangzhou, China. J Expo Sci Environ Epidemiol. 2018;28(4):392-9.

24. Temming P, Schultz C, Muller-Steinhardt M, Adam N, Hartel C, Strunk T. Cytokine responses correlate differentially with age in infancy and early childhood. Clin Exp Immunol. 2005 Dec 29;142(3):50929083117001.

25. Shearer WT, Rosenblatt HM, Gelman RS, Oyomopito R, Plaeger S, Stiehm ER, et al. Lymphocyte subsets in healthy children from birth through 18 years of age: the pediatric AIDS Clinical Trials Group P1009 study. J Allergy Clin Immunol. 2003 Nov;112(5):973-80. 
26. Shahabuddin S, al Ayed IH, El-Rad MO, Qureshi MI. Lymphocyte subset reference ranges in healthy Saudi Arabian children. Pediatr Allergy Immunol. 1998 Feb;9(1):44-8.

27. Thomas NJ, Jouvet P, Willson D. Acute lung injury in children - kids really aren't just "little Adults". Pediatr Crit Care Med. 2013 May;14(4):429-32.

28. Erickson SE, Shlipak MG, Martin GS, Wheeler AP, Ancukiewicz M, Matthay MA, et al. Racial and ethnic disparities in mortality from acute lung injury. Crit Care Med. 2009 Jan;37(1):1-6.

29. Jolley SE, Hough CL, Clermont G, Hayden D, Hou $\mathrm{S}$, Schoenfeld D, et al. Relationship between race and the effect of fluids on long-term mortality after Acute respiratory distress syndrome. Secondary analysis of the National Heart, Lung, and Blood Institute fluid and catheter treatment trial. Ann Am Thorac Soc. 2017 Sep;14(9):1443-9.

30. Perez-Marques F, Simpson P, Yan K, Quasney MW, Halligan N, Merchant D, et al. Association of polymorphisms in genes of factors involved in regulation of splicing of cystic fibrosis transmembrane conductance regulator mRNA with acute respiratory distress syndrome in children with pneumonia. Crit Care. 2016 Dec 5;20(1):281.

31. Reilly JP, Christie JD, Meyer NJ. Fifty years of research in ARDS. Genomic contributions and opportunities. Am J Respir Crit Care Med. 2017 Nov 1;196(9): 1113-21.

32. Sapru A, Liu KD, Wiemels J, Hansen H, Pawlikowska L, Poon A, et al. Association of common genetic variation in the protein $\mathrm{C}$ pathway genes with clinical outcomes in acute respiratory distress syndrome. Crit Care. 2016 Dec 23;20(1):151.

33. Meyer NJ, Feng R, Li M, Zhao Y, Sheu CC, Tejera $\mathrm{P}$, et al. IL $1 \mathrm{RN}$ coding variant is associated with lower risk of acute respiratory distress syndrome and increased plasma IL-1 receptor antagonist. Am J Respir Crit Care Med. 2013;187(9):950-9.

34. Dahmer MK, Quasney MW, Sapru A, Gildengorin G, Curley MAQ, Matthay MA, et al. Interleukin-1 receptor antagonist is associated with pediatric acute respiratory distress syndrome and worse outcomes in children with acute respiratory failure $*$. Pediatr Crit Care Med. 2018;19(10):930-8.

35. Shortt K, Chaudhary S, Grigoryev D, Heruth DP, Venkitachalam L, Zhang LQ, et al. Identification of novel single nucleotide polymorphisms associated with acute respiratory distress syndrome by exome-seq. Zhao YY, editor. PLoS One 2014 Nov 5;9(11):e111953.

36. Wei L, An Y, Wang J. Association between functional polymorphisms in the nitric oxide synthase 3 gene and pediatric acute respiratory distress syndrome. Genet Mol Res. 2016;15(3):17-8.

37. Bellani G, Laffey JG, Pham T, Fan E. The LUNG SAFE study: a presentation of the prevalence of ARDS according to the Berlin definition! Crit Care. 2016;20(1):268.
38. Eworuke E, Major JM, Gilbert McClain LI. National incidence rates for Acute respiratory distress syndrome (ARDS) and ARDS cause-specific factors in the United States (2006-2014). J Crit Care. 2018 Oct;47:192-7.

39. Sjoding MW, Hofer TP, Co I, McSparron JI, Iwashyna TJ. Differences between patients in whom physicians agree and disagree about the diagnosis of Acute Respiratory Distress Syndrome. Ann Am Thorac Soc. 2019;16(2):258-64. https://www.atsjournals. org/doi/10.1513/AnnalsATS.201806-434OC.

40. Bellani G, Laffey JG, Pham T, Fan E, Brochard L, Esteban A, et al. Epidemiology, patterns of care, and mortality for patients with acute respiratory distress syndrome in intensive care units in 50 countries. JAMA. 2016;315(8):788-800.

41. Kallet RH, Zhuo H, Ho K, Lipnick MS, Gomez A, Matthay MA. Lung injury etiology and other factors influencing the relationship between deadspace fraction and mortality in ARDS. Respir Care. 2017;62(10):1241-8.

42. Luo L, Shaver CM, Zhao Z, Koyama T, Calfee CS, Bastarache JA, et al. Clinical predictors of hospital mortality differ between direct and indirect ARDS. Chest. 2017;151(4):755-63.

43. Shah RD, Wunderink RG. Viral pneumonia and acute respiratory distress syndrome. Clin Chest Med. 2017;38(1):113-25.

44. Gralinski LE, Sheahan TP, Morrison TE, Menachery VD, Jensen K, Leist SR, et al. Complement activation contributes to severe acute respiratory syndrome coronavirus pathogenesis. Subbarao K, editor. MBio 2018 Oct 9;9(5) e01753-18.

45. Timmons O. Infection in pediatric Acute respiratory distress syndrome. Semin Pediatr Infect Dis. 2006;17(2):65-71.

46. Papazian L, Calfee CS, Chiumello D, Luyt CE, Meyer NJ, Sekiguchi H, et al. Diagnostic workup for ARDS patients. Intensive Care Med. 2016;42(5):674-85.

47. Raghavendran K, Nemzek J, Napolitano LM, Knight PR. Aspiration-induced lung injury. Crit Care Med. 2011;39(4):818-26.

48. Pfeifer R, Heussen N, Michalewicz E, Hilgers RD, Pape HC. Incidence of adult respiratory distress syndrome in trauma patients: a systematic review and meta-analysis over a period of three decades. J Trauma Acute Care Surg. 2017;83(3):496-506.

49. Calfee CS, Eisner MD, Ware LB, Thompson BT, Parsons PE, Wheeler AP, et al. Trauma-associated lung injury differs clinically and biologically from acute lung injury due to other clinical disorders. Crit Care Med. 2007;35(10):2243-50.

50. Killien EY, Mills B, Watson RS, Vavilala MS, Rivara FP. Risk factors on hospital arrival for acute respiratory distress syndrome following pediatric trauma. Crit Care Med. 2018;46(12):e1088-96.

51. de Roulet A, Burke RV, Lim J, Papillon S, Bliss DW, Ford HR, et al. Pediatric trauma-associated acute respiratory distress syndrome: Incidence, risk factors, 
and outcomes [Internet]. J Pediatr Surg. 2018; https:// doi.org/10.1016/j.jpedsurg.2018.07.005.

52. Ware LB. Pathophysiology of acute lung injury and the acute respiratory distress syndrome. Semin Respir Crit Care Med. 2006 Aug;27(4):337-49.

53. National Heart, Lung and BIACTN, Truwit JD, Bernard GR, Steingrub J, Matthay MA, Liu KD, et al. Rosuvastatin for sepsis-associated acute respiratory distress syndrome. N Engl J Med. 2014 Jun 5;370(23):2191-200.

54. Mckown AC, Mcguinn EM, Ware LB, Wang L, Janz DR, Rice TW, et al. Preadmission oral corticosteroids are associated with reduced risk of acute respiratory distress syndrome in critically III adults with sepsis. Crit Care Med. 2017;45(5):774-80.

55. Lieberman L, Petraszko T, Yi QL, Hannach B, Skeate R. Transfusion-related lung injury in children: a case series and review of the literature. Transfusion. 2014;54(1):57-64.

56. Mulder HD, Augustijn QJJ, van Woensel JB, Bos AP, Juffermans NP, Wösten-van Asperen RM. Incidence, risk factors, and outcome of transfusion-related acute lung injury in critically ill children: a retrospective study. J Crit Care. 2015;30(1):55-9.

57. Caudrillier A, Looney MR. Platelet-neutrophil interactions as a target for prevention and treatment of transfusion-related acute lung injury. Curr Pharm Des. 2012;18(22):3260-6.

58. Khan H, Belsher J, Yilmaz M, Afessa B, Winters JL, Moore SB, et al. Fresh-frozen plasma and platelet transfusions are associated with development of Acute lung injury in critically ill medical patients. Chest. 2007 May;131(5):1308-14.

59. Labarinas S, Arni D, Karam O. Plasma in the PICU: why and when should we transfuse? Ann Intensive Care. 2013 Jun 2;3(1):16.

60. Church GD, Matthay MA, Liu K, Milet M, Flori HR. Blood product transfusions and clinical outcomes in pediatric patients with acute lung injury*. Pediatr Crit Care Med. 2009 May;10(3):297-302.

61. Zhou MT, Chen CS, Chen BC, Zhang QY, Andersson R. Acute lung injury and ARDS in acute pancreatitis: mechanisms and potential intervention. World J Gastroenterol. 2010;16(17):2094-9.

62. Upperman JS, Bucuvalas JC, Williams FN, Cairns BA, Cox CS, Doctor A, et al. Specific etiologies associated with the multiple organ dysfunction syndrome in children: part 2. Pediatr Crit Care Med. 2017;18(3):S58-66.

63. Neto AS, Barbas CSV, Simonis FD, Artigas-Raventós A, Canet J, Determann RM, et al. Epidemiological characteristics, practice of ventilation, and clinical outcome in patients at risk of acute respiratory distress syndrome in intensive care units from 16 countries (PRoVENT): an international, multicentre, prospective study. Lancet Respir Med. 2016;4(11):882-93.

64. Matthay MA. Challenges in predicting which patients will develop ARDS. Lancet Respir Med. 2016 Nov;4(11):847-8.
65. Raymondos K, Dirks T, Quintel M, Molitoris U, Ahrens J, Dieck T, et al. Outcome of acute respiratory distress syndrome in university and non-university hospitals in Germany. Crit Care. 2017 Dec 30;21(1):122.

66. Noah MA, Peek GJ, Finney SJ, Griffiths MJ, Harrison DA, Grieve R, et al. Referral to an extracorporeal membrane oxygenation center and mortality among patients with severe 2009 influenza A(H1N1). JAMA. 2011 Oct 19;306(15):1659-68.

67. Einecke G, Beutel G, Hoeper MM, Kielstein JT. The answer is blowing in the wind: an uncommon cause for severe ARDS accompanied by circulatory insufficiency requiring extracorporeal membrane oxygenation. BMJ Case Rep. 2017;2017:1-5.

68. Chen HI. From neurogenic pulmonary edema to fat embolism syndrome: a brief review of experimental and clinical investigations of acute lung injury and acute respiratory distress syndrome. Chin J Physiol. 2009 Nov 30;52(5 Suppl):339-44.

69. Iglesias J, Sathiraju S, Marik PE. Severe systemic inflammatory response syndrome with shock and ARDS resulting from Still's disease: clinical response with high-dose pulse methylprednisolone therapy. Chest. 1999;115(6):1738-40.

70. Price L, Planche T, Rayner C, Krishna S. Acute respiratory distress syndrome in Plasmodium vivax malaria: case report and review of the literature. Trans R Soc Trop Med Hyg. 2007;101(7):655-9.

71. Rahman AKA, Sulaiman FN. Plasmodium vivax malaria presenting as acute respiratory distress syndrome: a case report. Trop Dr. 2013 Apr 24;43(2):83-5.

72. Sedý J, Zicha J, Kunes J, Jendelová P, Syková E. Mechanisms of neurogenic pulmonary edema development. Physiol Res. 2008;57(4):499-506.

73. Orwoll BE, Sapru A. Biomarkers in pediatric ARDS: future directions. Front Pediatr. 2016 Jun 1;4:55.

74. Sapru A, Flori H, Quasney MW, Dahmer MK. Pathobiology of acute respiratory distress syndrome. Pediatr Crit Care Med. 2015;16(5):S6-22.

75. Flori HR, Ware LB, Milet M, Matthay MA. Early elevation of plasma von Willebrand factor antigen in pediatric acute lung injury is associated with an increased risk of death and prolonged mechanical ventilation. Pediatr Crit Care Med. 2007 Mar;8(2):96-101.

76. Yehya N, Thomas NJ, Meyer NJ, Christie JD, Berg RA, Margulies SS. Circulating markers of endothelial and alveolar epithelial dysfunction are associated with mortality in pediatric acute respiratory distress syndrome. Intensive Care Med. 2016;42:1137-45.

77. Flori HR, Ware LB, Glidden D, Matthay MA. Early elevation of plasma soluble intercellular adhesion molecule-1 in pediatric acute lung injury identifies patients at increased risk of death and prolonged mechanical ventilation. Pediatr Crit Care Med. 2003 Jul;4(3):315-21.

78. Orwoll BE, Spicer AC, Zinter MS, Alkhouli MF, Khemani RG, Flori HR, et al. Elevated soluble thrombomodulin is associated with organ failure and mortality in children with acute respiratory 
distress syndrome (ARDS): a prospective observational cohort study. Crit Care. 2015;19:435.

79. Sapru A, Curley MAQ, Brady S, Matthay MA, Flori H. Elevated PAI-1 is associated with poor clinical outcomes in pediatric patients with acute lung injury. Intensive Care Med. 2010 Jan;36(1):157-63.

80. Yehya N, Thomas NJ, Margulies SS. Circulating nucleosomes are associated with mortality in pediatric acute respiratory distress syndrome. Am J Physiol Lung Cell Mol Physiol. 2016;310(11):L1177-84.

81. Curley MAQ, Wypij D, Watson RS, Grant MJC, Asaro LA, Cheifetz IM, et al. Protocolized sedation vs usual care in pediatric patients mechanically ventilated for acute respiratory failure: a randomized clinical trial. JAMA. 2015 Jan 27;313(4):379-89.

82. Frank AJ, Thompson BT. Pharmacological treatments for acute respiratory distress syndrome. Curr Opin Crit Care. 2010 Feb;16(1):62-8.

83. Prescott HC, Calfee CS, Thompson BT, Angus DC, Liu VX. Toward smarter lumping and smarter splitting: rethinking strategies for sepsis and acute respi- ratory distress syndrome clinical trial design. Am J Respir Crit Care Med. 2016 Jul 15;194(2):147-55.

84. Iwashyna TJ, Burke JF, Sussman JB, Prescott HC, Hayward RA, Angus DC. Implications of heterogeneity of treatment effect for reporting and analysis of randomized trials in critical care. Am J Respir Crit Care Med. 2015 Nov 1;192(9):1045-51.

85. Famous KR, Delucchi K, Ware LB, Kangelaris KN, Liu KD, Thompson BT, et al. Acute respiratory distress syndrome subphenotypes respond differently to randomized fluid management strategy. Am J Respir Crit Care Med. 2017;195(3):331-8.

86. Calfee CS, Delucchi K, Parsons PE, Thompson BT, Ware LB, Matthay MA. Subphenotypes in acute respiratory distress syndrome: latent class analysis of data from two randomised controlled trials. Lancet Respir Med. 2014;2(8):611-20.

87. Delucchi K, Famous KR, Ware LB, Parsons PE, Thompson BT, Calfee CS, et al. Stability of ARDS subphenotypes over time in two randomised controlled trials. Thorax. 2018 May;73(5):439-45. 